\title{
Proceeding
}

Supplementary Issue: Spring Conferences of Sports Science. Costa Blanca Sports Science Events, 19-20 June 2020. Alicante, Spain.

\section{Physical education teacher training for disability}

\author{
CHIARA CASCONE $\triangle$, GENOVEFFA ROSA DE CESARE, FRANCESCA D'ELIA \\ University of Salerno, Italy
}

\begin{abstract}
This work in focused on investigation of physical education teachers' education with pedagogical bases for students with disabilities. Starting from an American research on teachers of physical education who work in contact with the disability, it has shown how the teachers express negative attitudes towards inclusion because they consider their training inadequate. The aim is to understand the phenomenon of physical education teacher training analysing the documentary research of the master's degree programs in sports sciences in Italy, with a specific study on the master's degree in sports sciences at the university of Salerno and, finally, a survey on teachers' perception of disability. The first study revealed that the main difficulty encountered is the inability to plan inclusive and personalized lessons, since the degree courses refer to the bio-medical area. The second study, the analysis of the Master degree course of Science in Sports Science at the University of Salerno, mainly refers to the pedagogical-didactic area and aimed at teaching and designing for the purpose of education for the disabled. From the fact-finding survey on teachers' perceptions emerges that both pedagogy and teaching are fundamental for any job in the motor and sports field, even for those who decide not to teach. In conclusion, the training of the physical education teacher who also teaches the disabled must have a less bio-medical and more pedagogical education.
\end{abstract}

Keywords: Questionnaire; Social research; Special needs.

Cite this article as:

Cascone, C., de Cesare, G.R., \& D'Elia, F. (2020). Physical education teacher training for disability. Journal of Human Sport and Exercise, 15(3proc), S634-S644. doi:https://doi.org/10.14198//hse.2020.15.Proc3.16

Corresponding author. University of Salerno, Italy.

E-mail: c.cascone20@studenti.unisa.it

Supplementary Issue: Spring Conferences of Sports Science. Costa Blanca Sports Science Events, 19-20 June 2020. Alicante, Spain.

JOURNAL OF HUMAN SPORT \& EXERCISE ISSN 1988-5202

(c) Faculty of Education. University of Alicante

doi:10.14198/jhse.2020.15.Proc3.16 


\section{INTRODUCTION}

Through a systematic review of the scientific literature, and an American research (Rizzo, Folsom-Meek, 2002) conducted in the field of physical activity sciences and disability, it emerged that teachers of physical education often have difficulties approaching disability and show negative attitudes because they consider their training inadequate (Block, Obrusnikova, 2007). Physical education is the most important subject in secondary school for adaptive sport for disabled people (Viscione et al, 2019). The quantitative aspects of exercise and sport sciences has the relationship also for the performance and the risk of it (Sannicandro et al, 2017, 2016, 2015ab, 2014, 2012ab, 2011). Strengthen and its characteristics have the important role for the training of physical education teachers in consideration to implement the right program in the school (Sgrò et al, 2018, 2017ab, 2016, 2015) in presence of special need of performance (Izzo et al, 2020ab, lzzo et al, 2019abc). It should also consider the aspect for the swimming and training of physical education teacher, because this repetitive stance is almost constant and there is not the adequate physical and sport activities (Invernizzi et al, 2020, 2014ab, 2008). The phenomenon of physical education training have to be deep from the epistemological perspective of the educative a didactics action (D'Elia, 2019). Physical exercise and learning is the central question for the disabled people and have to be investigated for every quantitative and qualitative performances (Raiola, 2020 , Raiola et al, 2018, Raiola 2011ab). Aim is to understand the phenomenon of the training of teachers of physical education through a survey on the levels of education and measurement of the teachers' behaviours towards their pupils with disabilities during normal physical education lessons and subsequently, since it emerged that the difficulties are mainly due to reasons related to the training, a specific documentary analysis was carried out on the teachings of the master's degree in sports sciences of the University of Salerno.

\section{METHOD}

\section{Declination of the investigation method with related means and tools}

A semi-structured questionnaire was used to carry out the survey using the "Google forms" platform. The questionnaire was administered strictly anonymously and was spread through social contact methods such as Facebook and Telegram.

The questionnaire consists of three different sections:

- The first part consists of questions on the personal and professional profile of the interviewees;

- The second part consists of an adaptation of the PEATID scale, coded for physical education teachers in school with the full name of "Validating the physical educators' attitude toward teaching individuals with disabilities III (Peatid III) survey for future professionals, in" adapted physical activity quarterly ", which measures the attitude of physical educators towards the teaching of people with disabilities during regular physical education lessons (Rizzo and Folsom-Meek, 2002);

- The last part consists of three self-evaluation questions, on knowledge, training and experience lived at school.

From the data resulting from these questionnaires it emerges that many times the difficulties encountered depend on the training, for this reason we decided to focus on the University of Salerno, carrying out an archive search through the research portal https://www.universitaly.it/

The Faculty of Sports Sciences is centred from an educational pedagogical point of view and takes the name of Sciences of motor-sports evaluation and analysis and design techniques of sport for the disabled, which 
provides adequate pedagogical and planning preparation to cope to the different needs of pupils, especially those with disabilities.

\section{RESULTS WITH STATISTICAL MODEL}

\section{Analysis of the results}

The "Microsoft Excel" software was used for data analysis. The sample examined is made up of 200 professional kinesiologists, i.e. graduates in Sport Sciences, of this: $53 \%$ play the role of teacher at the first and second grade secondary schools; $47 \%$ play the role of specialist, i.e. tutor in primary school projects.

The number of years of service provided at school, including the current year, in any role played, varies in very homogeneous percentages from a few years to more than 9 , to be precise: $36 \%$ have been in the school world for more than 9 years; $28.5 \%$ have been in the school world for less than 3 years; $24.5 \%$ are less than 6 years old; $11 \%$ have been in the school world for more than 9 years.

The sample is quite varied from different points of view: role, years of service, gender and age.

As for the age of the sample, the interval mainly included is that from 31 to 40 years with $36.5 \%$, the other intervals do not differ too much from the latter.

A heterogeneity was also found in the training of teachers, coming from different study paths. Most of the sample have a master's degree $(73.5 \%)$, while $26.5 \%$ have an ISEF diploma, but among the master's degrees we have different specializations.

There are 147 graduates in total and among these we have: three-year graduates with the old and new regulations (L22 Sciences of motor and sport activities); master's degrees in three different specializations, with the old and new regulations (LM47 Organization and management of services for sport and motor activities, LM67 Sciences and techniques of preventive and adapted motor activities, LM68 Sciences and techniques of sport) and ISEF graduates who subsequently obtained a master's degree. ISEF graduates, on the other hand, if we consider the differentiation also by the type of master's degree, are mostly together with LM67 graduates, that is 53 people (Figure 1).

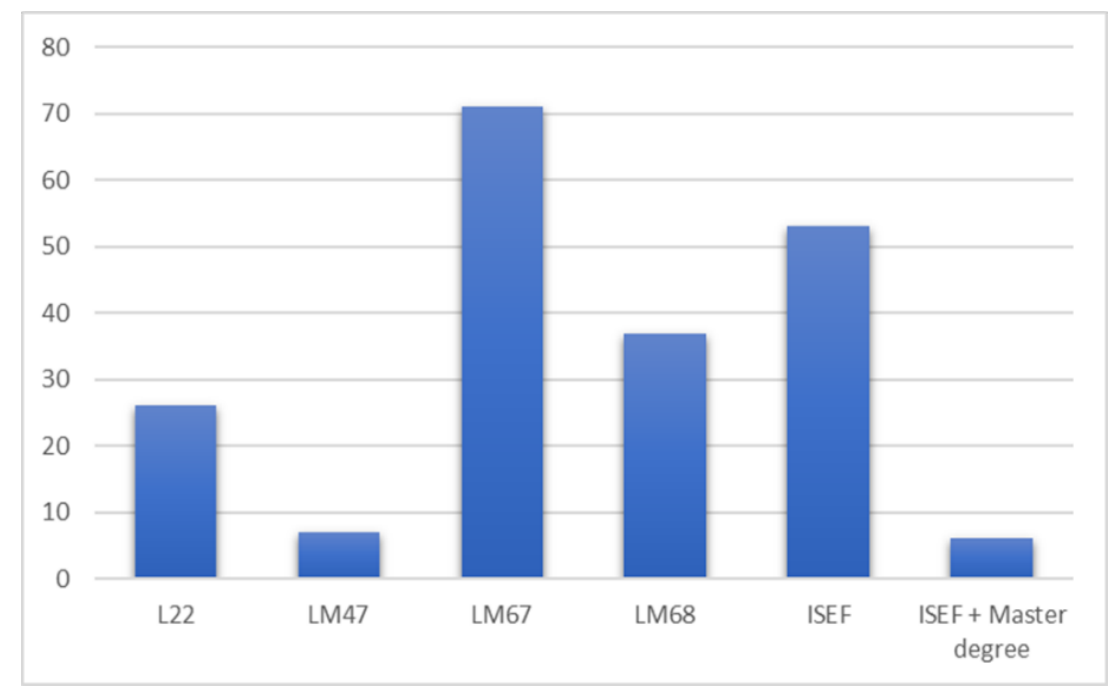

Figure 1. Number of people for each type of training. 
It is important to specify that in the research the specialist degrees of classes 53 / S, 75 / S and 76 / S have been equated with the same master's degrees, which have only seen a change of code in the Ministerial Decree 270/2004.

The sample does not refer to any particular region, but rather to all of Italy, the people who took the test come from 32 different universities. Even the service region is very varied, out of a sample of 200 people only two regions have never been indicated and all the others have very low percentages ranging from $0.5 \%$ to $10 \%$.

Furthermore, even if there is a $31 \%$ of people who have not achieved additional qualifications in the field of disability, there is a significant number of people who have followed training, specialization or master courses related to the topic (Figure 2):

- $39 \%$ have achieved $24 \mathrm{CFU}$ certification for teaching;

- $19 \%$ have a Master's degree;

- $11 \%$ have completed the TFA (specialization course in support).

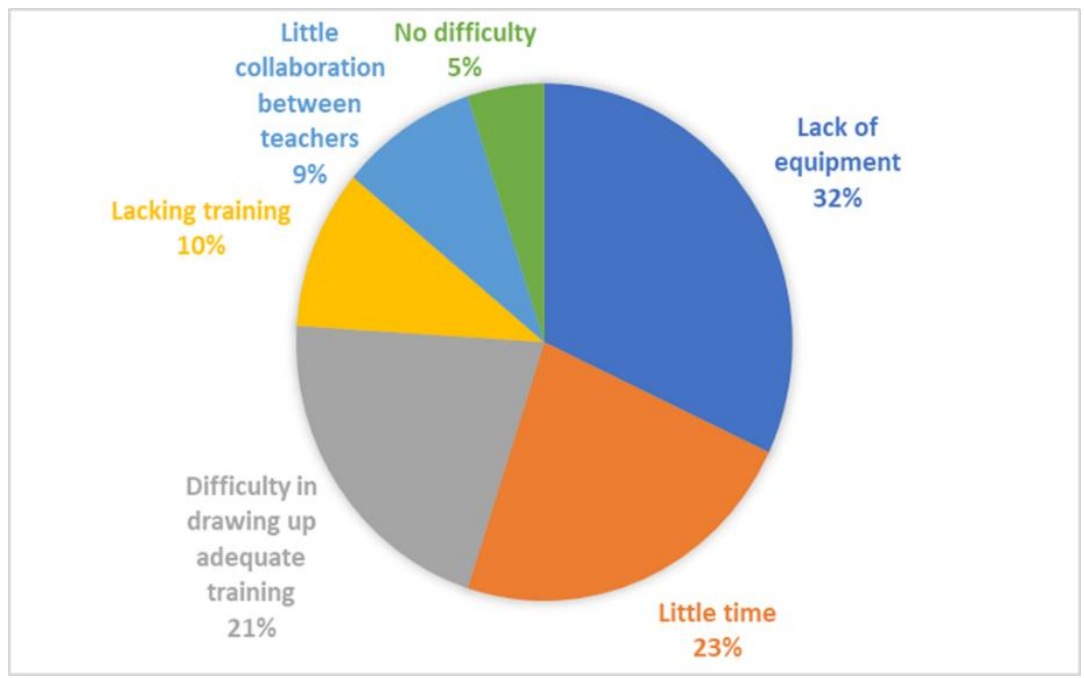

Figure 2. Percentages added qualifications related to the disability theme.

In their school experience $55.5 \%$ of the sample, (111 people) defined the amount of times they met children with some type of disability with the adverb "often", this percentage is very high if we consider that the other options do not reach more than $23 \%$ each (never, rarely and always) (Figure 3 ).

Furthermore, in the opinion of these professionals in motor practice, $45 \%$ think that children / young people with disabilities mainly need the professional figure of the support teacher, $30 \%$ think that the help of the entire teaching staff is necessary. Finally, only $19 \%$ think that the motor teacher is a professional figure useful for children with disabilities.

As for the second part of the survey, that relating to self-evaluation, only $47 \%$ of the kinesiology professionals believe they are fairly good at working together with other professionals such as support teachers, curricular teachers and other professional figures present within the school.

As regards, however, the type of exams taken during university education, especially exams in the field of disability (Cassese, Raiola, 2017), 38\%, the majority, say they have taken between two and four exams 
during their university course, while $18.5 \%$, therefore a high percentage anyway, say they have never even taken an exam concerning this area, because their specialization does not provide for it.

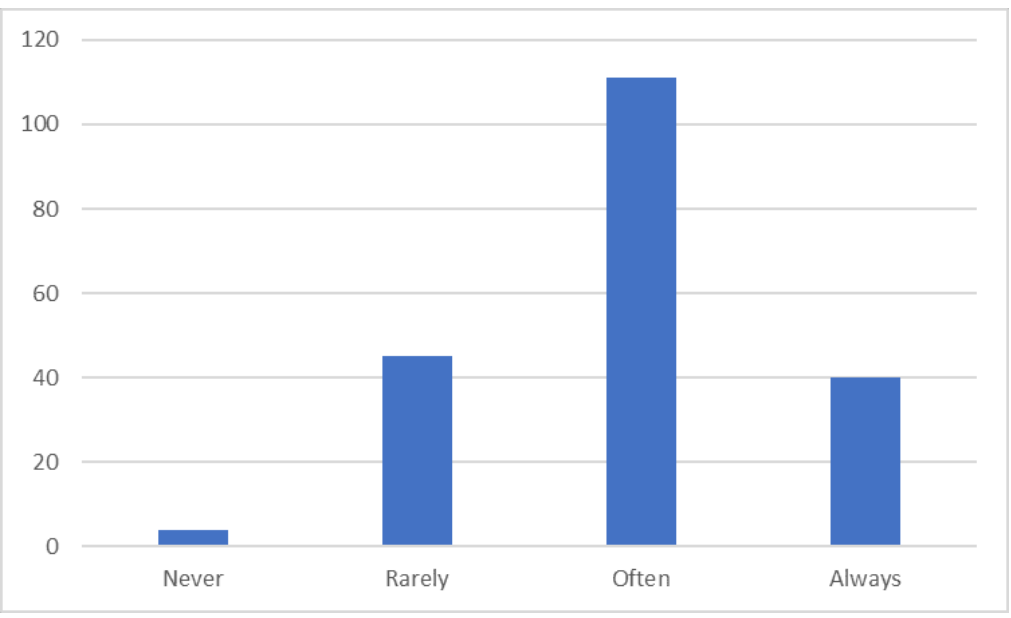

Figure 3. Experiences at school in relation to the number of times pupils with disabilities have had.

As regards, however, didactic-pedagogical knowledge, the situation is much better: in fact, $44 \%$ say they have achieved between two and four exams while $36 \%$ say they have achieved more than four, and only $5 \%$ never even played.

The self-assessment regarding knowledge related to disability legislation did not give excellent results (Figure 4):

- $\quad 48.5 \%$ call them "Sufficient";

- $10.5 \%$ say they don't have any;

- $6.5 \%$ define them as "Excellent";

- $34.5 \%$ define them as "good".

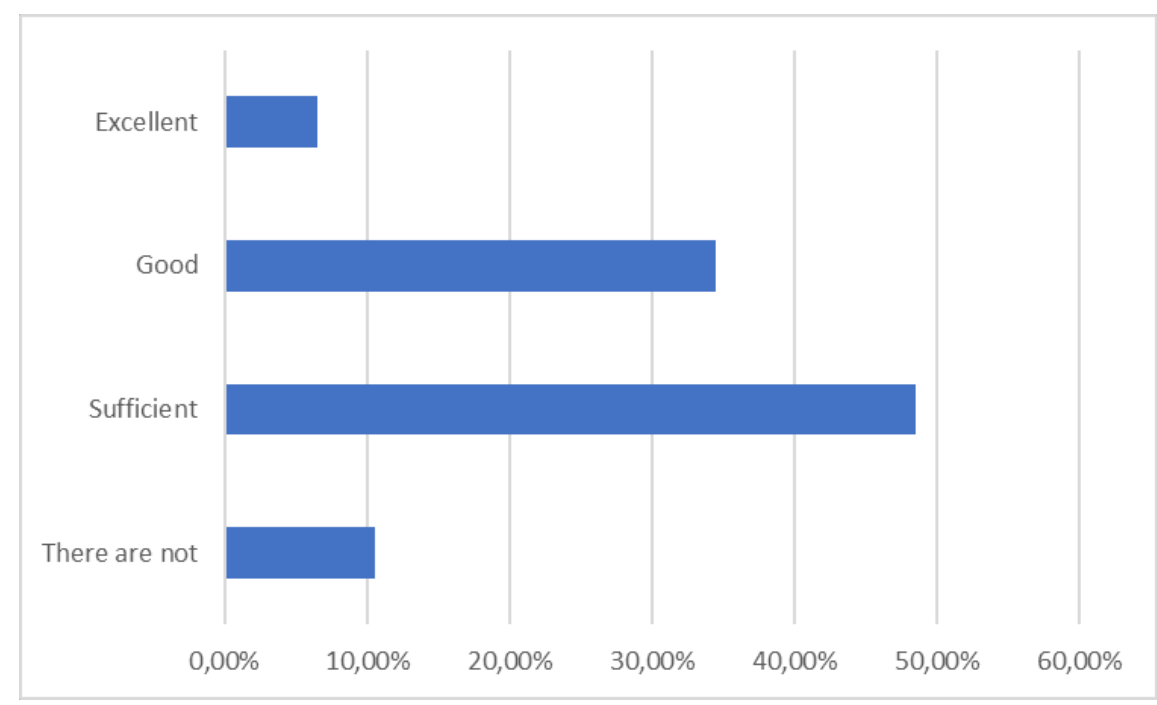

Figure 4. Percentages relative to the knowledge of the legislation on the disability of the sample. 
The main part of the survey concerns the difficulties encountered during experiences at school with disabled people. $32 \%$ blame the lack of adequate equipment; $23 \%$ at the limited times expected in class and $3 \%$ in the presence of mixed classes. The latter, $58 \%$ of the sample, identify the origin of their difficulties in external causes, $34 \%$ admit, however, that they are the cause of the problem among them: $21 \%$ admit a difficulty in drawing up an adequate programming for their own students; $10 \%$ believe they do not have a suitable university education and $3 \%$ blame the lack of or absent collaboration between teachers. Finally, only a very small part, $8 \%$ say they have never had difficulties with the disabled (Figure 5).

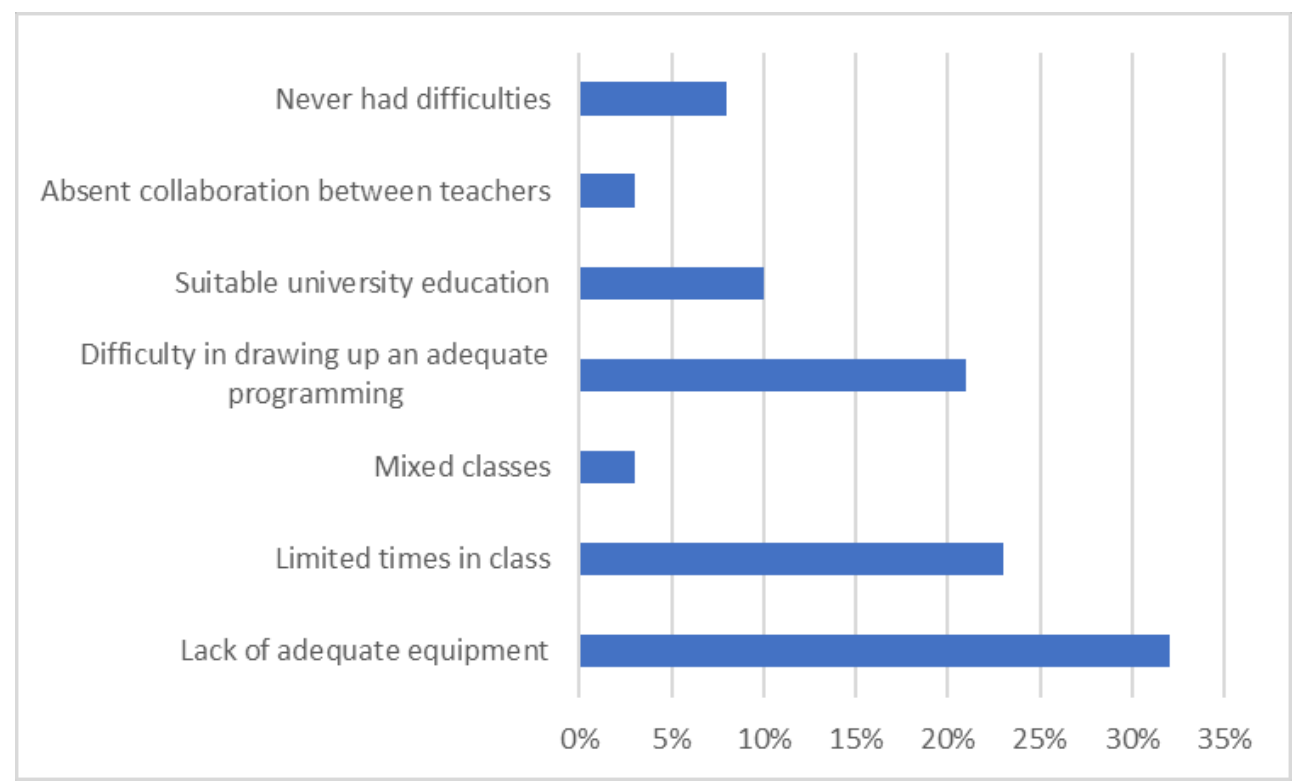

Figure 5. Difficulties encountered in experiences at school with disabled people.

To test with which of the disabilities there was greater safety, and with which instead, greater difficulties, the frequency with which each disability could be included in its own motor activity lesson was requested:

- The majority replied that children with Special Educational Needs (BES) and Specific Learning Disorders (DSA) are the categories of disabilities that present less difficulties, which is why they can "always" be included;

- Regarding students with sensory, intellectual and psychic disabilities, the majority replied that they can be "often" included, therefore the sample shows a greater difficulty than the previous mentioned disabilities;

- Finally, with regard to motor disabilities, the majority claims to be able to include them only "every now and then", underlining how this is the disability of which professionals are most "afraid" and, classifying it as the most complicated disability to manage.

In the last part of the questionnaire, that is, the one concerning the "PEATID" test, most of them claim to be "Totally disagree" regarding derogatory statements such as (Figure 6):

- Pupils with disabilities will not be accepted by classmates;

- Pupils with disabilities will disturb the harmony of the class;

- Pupils with disabilities will place an unfair workload on me;

- Pupils with disabilities should not be part of my lessons;

- Pupils with disabilities should be part of my lessons only when possible. 


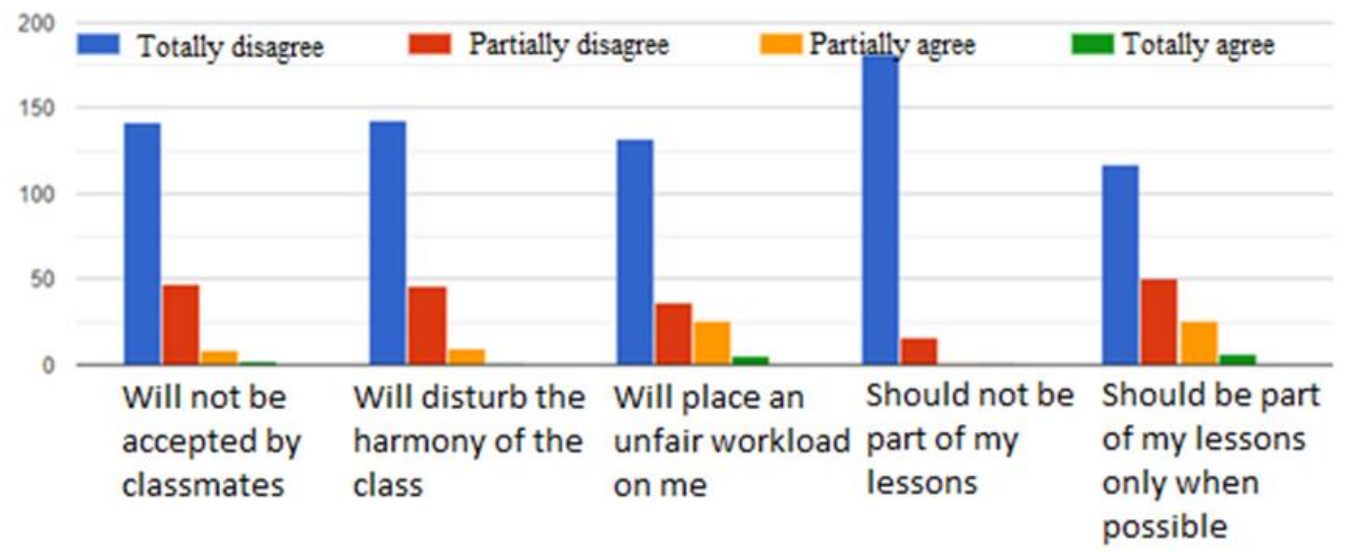

Figure 6. PEATID scale (derogatory statements).

Regarding, however, positive affirmations, the majority of teachers move to the value "Totally agree" (Figure 7):

- Pupils with disabilities will benefit their classmates;

- Pupils with disabilities will be helped by their classmates;

- Pupils with disabilities will learn faster thanks to their classmates;

- Pupils with disabilities will develop better self-esteem.

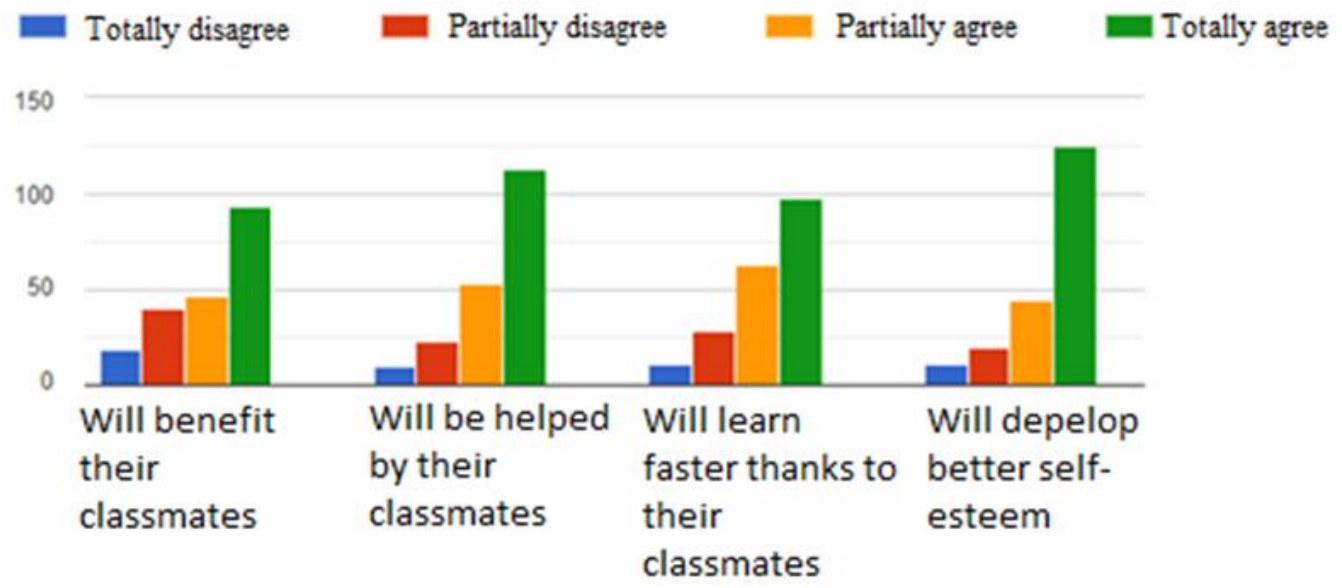

Figure 7. PEATID scale (positive affirmations).

Based on their knowledge and skills as educators, the majority of the sample agrees that they have sufficient experience, adequate preparation and have the ability to evaluate their pupils with disabilities (Figure 8). As far as these issues are concerned, the majority is not clear-cut. 


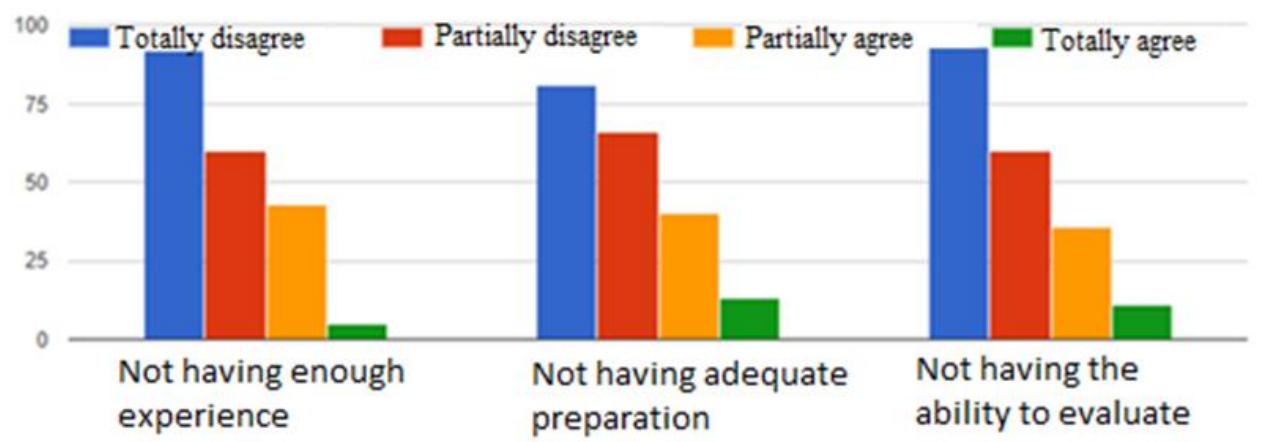

Figure 8. Self-Assessment questions.

From the data we can see that the problems encountered, in most cases, are ascribable to training and for this reason, research was carried out on the LM-68 degree of the University of Salerno, which provides adequate preparation to respond to the various difficulties and takes the name of Sciences of motor-sport evaluation and analysis and design techniques of sport for the disabled. It aims to: prepare professionals and teachers specialized in the education and training of disabled people; train non-competitive sport instructors, event organizers and sports facilities; become coaches and technicians of competitive sports.

This Degree course has a recent history, since it was activated in the academic year 2009/2010 at the University of Salerno and partially responds to the demand for training of the new generations. The Degree course, in the past, was located in the scientific area, as it is based on the biomedical field, but with the establishment of the L-22 course from 2014/2015 it presents a new connotation from the pedagogical-didactic point of view. In fact, not only students from ISEF and class L-22, but also graduates from class L-19 can access the course, extending the educational opportunities. The course allows graduates to participate in the selections to access the qualification for teaching physical education in first and second grade secondary schools and prepares technological-didactic, analysis and planning skills, which can be spent in schools, at partner structures. -educational, in professional and amateur sports, with particular reference to the field of disability. Among the characterizing exams, there is:

- M-PED / 03: "Methodology of didactic research and elements of special pedagogy": Special pedagogy aims to promote the concept of participation, critical reflection on possible didacticpedagogical paths and trends that can improve the body size of people with needs special education, both in school and out of school contexts; Methodology of didactic research allows to provide students with the theoretical background, practical tools and aptitudes to interpret, critically analyse and design research in the educational-didactic field, with particular attention to physical and sporting activities for learners with special educational needs;

- M-EDF / 01: "Methods and techniques of psycho-motor assessment", "Design and teaching of special motor activities" have the objective of providing the basic elements for the design of movement analysis procedures with the help or not of technological supports;

- M-EDF / 02: "Techniques and assessment of sporting aptitudes", "Theory, technique and didactics of sport for the disabled", focus on the design and evaluation elements of the individual adapted sports disciplines and on the teaching and sports training for the disabled. 
From what emerges from what has been said previously, we can say that the University of Salerno provides an important contribution to the educational-didactic training of its students, so that each graduate has an adequate curriculum.

It is articulated through the identification of the condition of each subject entrusted to their care and of which the teacher / coach / educator must take responsibility for guiding the development process and capable of selecting and modifying the contents of their teaching and making flexible response strategies to the needs recognized in their students.

\section{DISCUSSION}

As we've seen the research has shown that the greatest difficulty is given by the inability of Physical Education teachers to customize their educational-didactic action to measure the pupil with disabilities. Diversity and therefore being disabled is a value that the teacher must take into account concretely. For this reason, it is necessary to build training courses that give anyone the best chance development through "personalized" educational courses, that is, respectful of personal uniqueness. The right to receive education is also realized in the full participation of the student in the educational activities implemented in the gym.

\section{CONCLUSIONS}

In conclusion, the main difficulty that professional figures face at school is the inability to plan inclusive and personalized lessons. For this reason, the training of the physical education teacher in general, and in particular for those who teach the disabled, must have a less bio-medical and more pedagogical training in order to be able to relate effectively.

\section{REFERENCES}

Block M., Obrusnikova I. (2007), "Inclusion in Physical Education: A Review of the Literature From 19952005", in «Adapted Physical Activity Quarterly» cit., p. 117. https://doi.org/10.1123/apaq.24.2.103

D'Elia, F., Raiola, G. (2019) Sport and Exercise Sciences Degrees in Italy: Comparison Between Online and Traditional Teaching Models, Communications in Computer and Information Science, 1091, pp. 209-216. https://doi.org/10.1007/978-3-030-31284-8_16

Invernizzi, P.L., Signorini, G., Bosio, A., Raiola, G., Scurati, R. (2020) Validity and reliability of selfperception-based submaximal fitness tests in young adult females: An educational perspective Sustainability, 12 (6). https://doi.org/10.3390/su12062265

Invernizzi, P.L., Limonta, E., Bosio, A., Scurati, R., Veicsteinas, A., Esposito, F. (2014a) Effects of a 25$\mathrm{km}$ trial on psychological, physiological and stroke characteristics of short- And mid-distance swimmers Journal of Sports Medicine and Physical Fitness, 54 (1), pp. 53-62.

Invernizzi, P.L., Longo, S., Scurati, R., Maggioni, M.A., Michielon, G., Bosio, A. (2014b) Interpretation and perception of slow, moderate, and fast swimming paces in distance and sprint swimmers Perceptual and Motor Skills, 118 (3), pp. 833-849. https://doi.org/10.2466/27.29.pms.118k23w0

Invernizzi, P.L., Longo, S., Scurati, R. (2008) Analysis of heart rate and lactate concentrations during coordinative tasks: Pilot study in karate kata world champions Sport Sciences for Health, 3 (1-2), pp. 41-46. https://doi.org/10.1007/s11332-008-0053-7

Izzo, R., Raiola, G., D'isanto, T., Cejudo, A., Giovanelli, G.M. (2020a) Modelling an adequate profile for a more targeted work methodology, with dedicated technologies, for elite-level footballers: Comparison between sub 17 vs sub 19, highlights and shadows, Sport Science, 13 (1), pp. 36-42. 
Izzo, R., D'isanto, T., Raiola, G., Cejudo, A., Ponsano, N., Varde'i, C.H. (2020b) The role of fatigue in football matches, performance model analysis and evaluation during quarters using live global positioning system technology at 50hz, Sport Science, 13 (1), pp. 30-35.

Izzo, R., Giovannelli, M., Raiola, G. (2019a) Training load in elite goalkeepers with k-track for monitoring performance, Journal of Physical Education and Sport, 19, art. no. 280, pp. 1890-1896.

Izzo, R., Giovannelli, M., D'isanto, T. (2019b) The injury prevention program WTA functional primitive movement in professional football players: A case study Journal of Physical Education and Sport, 19 , art. no. 279 , pp. 1885-1889.

Raiola, G. (2020) The Movement and Sport Science in Italy towards the European Research Council, Physical Culture and Sport, Studies and Research, 86 (1), pp. 37-48. https://doi.org/10.2478/pcssr2020-0011

Raiola, G. (2017) Motor learning and teaching method, Journal of Physical Education and Sport, 17, art. no. 236, pp. 2239-2243.

Raiola, G., D'elia, F., Altavilla, G. (2018) Physical activity and sports sciences between European Research Council and academic disciplines in Italy, Journal of Human Sport and Exercise, 13, pp. S283-S295. https://doi.org/10.14198/hse.2018.13.proc2.13

Raiola, G. (2011a) A study on Italian primary school rules: Neurophysiological and didactics aspects on physical education and sport, Journal of Physical Education and Sport, 11 (2), pp. 43-48.

Raiola, G. (2011b) Study between neurophysiological aspects and regulation documents on preschool in Italy, Journal of Physical Education and Sport, 11 (1), pp. 42-47.

Sannicandro, I. (2017) Effects of strength and core stability training versus strength and aerobic training in subjects aged over 65 [Article@Effetti dell'allenamento di forza e core stability versus allenamento di forza e aerobico a intensità controllata in soggetti over 65] Medicina dello Sport, 70 (4), pp. 410 418.

Sannicandro, I., Cofano, G., Rosa, A.R. (2016) Heart rate response comparison of young soccer plyers in "cage" small-sided and 8vs8 games Journal of Physical Education and Sport, 16 (4), art. no. 180, pp. 1122-1127.

Sannicandro, I., Spedicato, M., Palaia, G., Cofano, G., Bisciotti, G.N., Eirale, C. (2015a) Strength ability, endurance and anthropometric parameters in youth football: Descriptive analysis and functional relationships [Article@Capacità di forza, endurance e parametri antropometrici nel calcio giovanile: Analisi descrittiva e rapporti funzionali] Medicina dello Sport, 68 (1), pp. 19-30.

Sannicandro I. (2015b) Descriptive analysis and functional relationships [Medicina dello Sport, 68 (1), pp. $19-30$.

Sannicandro, I., Piccinino, A., Cofano, G., Eirale, C., Biscotti, G.N. (2014) Effects of plyometric training on phases of jumping in young fencers Medicina dello Sport, 67 (1), pp. 27-45.

Sannicandro, I., Piccinno, A., Cofano, G., De Pascalis, S., Rosa, A.R. (2012a) Analysis of some variable performances of under 12 tennis players [Article@Analisi di alcune variabili prestative del giovane tennista under 12] Medicina dello Sport, 65 (4), pp. 473-484.

Sannicandro, I., Rosa, R.A., De Pascalis, S., Piccinno, A. (2012b) The determination of functional asymmetries in the lower limbs of young soccer players using the countermovement jump. The lower limbs asymmetry of young soccer players Science and Sports, 27 (6), pp. 375-377. https://doi.org/10.1016/i.scispo.2011.11.001

Sannicandro, I. Evaluation of muscle strength in young and top-level soccer players (2011) Medicina dello Sport, 64 (1), pp. 9-20.

Sgrò, F., Pignato, S., Lipoma, M. (2018) Assessing the impact of gender and sport practice on students 'performance required in team games Journal of Physical Education and Sport, 18, art. no. 71, pp. 497-502. 
Sgrò, F., Quinto, A., Messana, L., Pignato, S., Lipoma, M. (2017a) Assessment of gross motor developmental level in italian primary school children Journal of Physical Education and Sport, 17 (3), art. no. 192, pp. 1954-1959.

Sgrò, F., Mango, P., Pignato, S., Schembri, R., Licari, D., Lipoma, M. (2017b) Assessing Standing Long Jump Developmental Levels Using an Inertial Measurement Unit Perceptual and Motor Skills, 124 (1), pp. 21-38. https://doi.org/10.1177/0031512516682649

Sgro', F., Quinto, A., Pignato, S., Lipoma, M. (2016) Comparison of product and process oriented model accuracy for assessing countermovement vertical jump motor proficiency in pre-adolescents Journal of Physical Education and Sport, 16 (3), art. no. 145, pp. 921-926.

Sgrò, F., Licari, D., Coppola, R., Lipoma, M. (2015) Assessment of balance abilities in elderly people by means of a clinical test and a low-cost force plate Kinesiology, 47 (1), pp. 33-43.

Viscione, I., Invernizzi, P.L., Raiola, G. (2019). Physical education in secondary higher school. Journal $\begin{array}{llll}\text { of Human Sport and Exercise, } 14 \text { (Proc4), pp. S706-S712. } & \text { S }\end{array}$ https://doi.org/10.14198/jhse.2019.14.proc4.31 